\title{
CYP21A2 polymorphisms in patients with autoimmune Addison's disease, and linkage disequilibrium to HLA risk alleles
}

\author{
Ingeborg Brønstad', Beate Skinningsrud ${ }^{2}$, Eirik Bratland ${ }^{1}, K_{\text {Kristian Løvås }}^{1,3}$, \\ Dag Undlien $^{2,4}$, Eystein Sverre Husebye ${ }^{1,3}$ and Anette Susanne Bøe Wolff ${ }^{1}$ \\ ${ }^{1}$ Department of Clinical Science, University of Bergen, Laboratory building, 8th floor, Bergen 5021, Norway, \\ ${ }^{2}$ Department of Medical Genetics, Oslo University Hospital, Oslo 0407, Norway, ${ }^{3}$ Department of Medicine, \\ Haukeland University Hospital, Bergen 5021, Norway and ${ }^{4}$ Institute of Medical Genetics, University of Oslo, \\ Oslo 0315, Norway
}

Correspondence should be addressed to I Brønstad Email

Ingeborg.Bronstad@ k2.uib.no

\begin{abstract}
Objective: Steroid 21-hydroxylase, encoded by CYP21A2, is the major autoantigen in autoimmune Addison's disease (AAD). CYP21A2 is located in the region of the HLA complex on chromosome 6p21.3, which harbours several risk alleles for AAD. The objective was to investigate whether CYP21A2 gene variants confer risk of AAD independently of other risk alleles in the HLA loci.

Design: DNA samples from 381 Norwegian patients with $A A D$ and 340 healthy controls $(H C)$ previously genotyped for the HLA-A, $-B,-D R B 1$, and $-D Q B 1$ and MICA loci were used for genotyping of CYP21A2.

Methods: Genotyping of CYP21A2 was carried out by direct sequencing. Linkage of CYP21A2 to the HLA loci was assessed using UNPHASED version 3.0.10 and PHASE version 2.1.

Results: Heterozygotes of the single-nucleotide polymorphisms (SNPs) rs397515394, rs6467, rs6474, rs76565726 and rs6473 were detected significantly more frequently in AAD patients compared with $\mathrm{HC}(P<0.005)$, but all SNPs were in a linkage disequilibrium (LD) with high-risk HLA-DRB1 haplotypes. rs $6472 \mathrm{C}$ protected against $\mathrm{AAD}$ (odds ratio $=0.15,95 \% \mathrm{Cl}(0.08$ $\left.0.30), P=3.8 \times 10^{-10}\right)$. This SNP was not in an LD with HLA loci $(P=0.02)$, but did not increase protection when considering the effect of HLA-DRB1 alleles. Mutations causing congenital adrenal hyperplasia were found in heterozygosity in $<1.5 \%$ of the cases in both groups.

Conclusion: Genetic variants of CYP21A2 associated to AAD are in LD with the main AAD risk locus HLA-DRB1, and CYP21A2 does not constitute an independent susceptibility locus.
\end{abstract}

\section{Introduction}

Autoimmune Addison's disease (AAD) is caused by the destruction of hormone-producing cells in the adrenal cortex by autoreactive immunological mechanisms. AAD often occurs together with other organ-specific autoimmune disorders, as part of autoimmune polyendocrine syndromes types 1 and 2 (APS1 and APS2 respectively) $(1,2)$. APS1 is a rare monogenic autosomal recessive disease caused by mutations in the autoimmune regulator (AIRE) gene (3). Isolated AAD and APS2, however, are thought to be caused by susceptibility variants of multiple genes interacting with environmental triggers. To date, the HLA class II haplotypes DRB1*03:01 and DRB1*04:04 have been shown to be the strongest predisposing genetic factors for AAD with odds ratio (OR) of 2.9 and 3.3 (4) respectively. Risk is particularly high when these haplotypes are combined $(\mathrm{OR}=32)(2)$. The HLA-class I genes $H L A-A$ and $H L A-B\left(\mathrm{OR}=2.6\right.$ of $\left.H L A-B{ }^{*} O 8\right)$ and MHC-class I-related chain A (MICA) also harbour the AAD risk alleles
(C) 2014 European Society of Endocrinology Printed in Great Britain
Published by Bioscientifica Ltd. 
$(4,5,6,7)$. In addition, several other genes related to the immune system have been associated with AAD: cytotoxic T lymphocyte antigen-4 (CTLA-4) $(8,9)$, protein tyrosine phosphatase non-receptor type 22 (PTPN22) $(10,11)$, MHC class II transactivator (CIITA), C-type lectin domain family 16, member A (CLEC16A) (12), cytochrome P450, family 27 , subfamily B, polypeptide 1 (CYP27B1) $(13,14)$ and programmed death ligand (PD-L1) (15).

The major autoantigen in AAD is the enzyme steroid 21-hydroxylase $(21 \mathrm{OH})$, which is expressed mainly in the adrenal cortex (16), and circulating autoantibodies (Ab) against $21 \mathrm{OH}$ are present in more than $84 \%$ of patients with AAD in various European cohorts $(2,17,18,19)$. $21 \mathrm{OH}$ is encoded by CYP21A2, and mutations in this gene are the main cause of congenital adrenal hyperplasia (CAH) (20). Polymorphisms and mutations in CYP21A2 are common, mainly due to the presence of the structurally related pseudogene CYP21A1P (21). The variants in CYP21A2 may potentially have an impact on the immunogenicity of $21 \mathrm{OH}$ and thereby influence the chance of an autoreactive response being directed towards it. The examples of such effects are seen in type 1 diabetes where autoantibody frequencies towards the zinc transporter eight (SLC3OA8) are dependent on which isoform is expressed (22). Moreover, different isoforms of the thyroid-stimulating hormone receptor (TSHR) vary in their immunogenicity $(23,24)$. The expression of CYP21A2 in thymic medullary cells could potentially be dependent on polymorphisms, thereby influencing negative selection of $21 \mathrm{OH}$-specific $\mathrm{T}$ cells.

We therefore investigated whether CYP21A2 is a susceptibility gene for AAD. Previously, two studies have addressed CYP21A2 polymorphisms in relationship with the risk of developing AAD without finding any diseasespecific variants $(25,26)$. However, both studies were underpowered; the largest cohort included 24 patients with AAD. In this study, we analysed the much larger wellcharacterised Norwegian cohort $(n=381)$. As CYP21A2 is located on chromosome 6p21.3 in the HLA-III locus, which is in strong linkage disequilibrium (LD) with the $H L A$-I and II loci, such a large sample size is required to determine whether potential CYP21A2 variants add to the risk of AAD independently of the HLA loci.

\section{Subjects and methods}

\section{Subjects}

A total of 381 patients with AAD ( $64 \%$ females, $36 \%$ males; mean age 58 years) were recruited from the National
Norwegian Registry of patients with Addison's disease (2) and 340 anonymous Norwegian blood donors controls (healthy controls (HC)) were available for genetic analyses. $21 \mathrm{OH}$ autoantibody index values as determined by RIA were available for all patients (2). AAD was diagnosed in patients with adrenal insufficiency with either a positive $21 \mathrm{OH}-\mathrm{Ab}$ test, or adrenal insufficiency combined with another endocrine autoimmune disease. Of the $381 \mathrm{AAD}$ patients, $92 \%$ were positive for $21 \mathrm{OH}-\mathrm{Ab}$, and $58 \%$ had APS2 (Addison's disease plus autoimmune thyroid disease and/or type 1 diabetes), while $34 \%$ had isolated AAD.

\section{Ethics}

All included patients and blood donors signed a written consent form. The study was approved by the Regional Committee for Medical Ethics of Western Norway and carried out according to the Helsinki declaration.

\section{Genetic analyses}

DNA was isolated from whole blood using standard commercial kits. The sequence of the whole CYP21A2 gene, including ten exons and nine introns, were analysed in 85 patients with AAD. As the antigenicity of $21 \mathrm{OH}$ most likely would be located in the coding regions, coding polymorphisms and rare variants detected in the 85 patients were sought for in a larger material of AAD patients $(n=381)$ and HC $(n=340)$. The CYP21A2 gene was amplified in two different fragments using primers discriminating the pseudogene from the functional CYP21A2 gene. The primers specific for CYP21A2 were targeted to the eight base pair (bp) deletion regions in exon 3 and the exon 6 cluster regions, which are the major markers for distinguishing the pseudogene from CYP21A2. The first primer pair amplified a fragment starting with the promoter region and ending with the four-point mutation region in exon 6 (21) (fragment 1); the second primer pair amplified the gene from exon 3 spanning the eight bp deletion region (21) to 170 bp of the $3^{\prime}$ end from exon 10 (fragment 2). Expand high fidelity PCR system (Roche) was used for amplifying PCR fragment 1; the thermal cycling protocol consisted of an initial denaturation step at $94^{\circ} \mathrm{C}$ for $2 \mathrm{~min}$, followed by ten cycles of denaturation at $94{ }^{\circ} \mathrm{C}$ for $15 \mathrm{~s}$, annealing at $55^{\circ} \mathrm{C}$ for $30 \mathrm{~s}$ and elongation at $72^{\circ} \mathrm{C}$ for $2.5 \mathrm{~min}$. Then the cycle was repeated 20 times with an increment of $5 \mathrm{~s}$ for each cycle. The PCR was terminated by an elongation step at $72^{\circ} \mathrm{C}$ for 7 min. AmpliTaq Gold with Gene Amp PCR system (Life Technologies) was used for amplifying PCR fragment 2; the thermal cycling conditions were initial denaturation at 
$96{ }^{\circ} \mathrm{C}$ for $10 \mathrm{~min}$, followed by 35 cycles of $94{ }^{\circ} \mathrm{C}$ for $20 \mathrm{~s}$, $54{ }^{\circ} \mathrm{C}$ for $20 \mathrm{~s}$ and $72^{\circ} \mathrm{C}$ for $2.5 \mathrm{~min}$. The final elongation step was run at $72^{\circ} \mathrm{C}$ for $7 \mathrm{~min}$. The variants and singlenucleotide polymorphisms (SNP) of CYP21A2 were identified by direct sequencing using standard conditions on an ABI 3730 DNA analyser. The primers (purchased from Eurogentec, Seraing, Liège, Belgium) of PCR and sequencing reactions have been described previously $(27,28,29)$. Sequencing data were aligned to the CYP21A2 gene sequence (http://www.ncbi.nlm.nih.gov/nuccore/ M12792.1). As a quality control to check that the pseudogene was not amplified in the PCR product, we checked that no pseudogene variants were present in the sequences. The copy number of the CYP21A2 gene was determined in AAD patients and HC by duplex real time PCR method (30). The genotyping of $H L A-A,-B,-D R B 1$ and $-D Q B 1$, and MICA was described previously by (4).

\section{Statistical analyses}

$\chi^{2}$ and Fisher's exact tests for the determination of significant differences between genotype and allele frequencies of patients and HC, grouped according to age at diagnosis, patients with or without type 1 diabetes or thyroid disease and gender; and calculations of OR with 95\% CIs were performed by IBM SPSS Statistics 20 using significance level of $P<0.05$. The calculation of Hardy-Weinberg equilibrium ( $P>0.001$ cutoff) and LD map of the CYP21A2 gene SNPs were performed by Haploview version 4.2 (31). Global association tests with conditional analysis for allele main effects were performed by UNPHASED version 3.0.10 (32) to determine whether the associations with CYP21A2 were independent $(P<0.05)$ of the HLA loci or not. Haplotype frequencies were generated by PHASE version 2.1 (33). D'Agostino and Pearson omnibus normality test was used to test whether the values of $210 \mathrm{H}$ index and age at diagnosis were distributed in a Gaussian manner, and Kruskal-Wallis test with Dunn's multiple comparison was used for testing differences between CYP21A2/HLA genotypes or haplotypes and $210 H$ antibody index values and mean age at diagnosis, using the Graph Pad Prism version 5.02 for Windows (GraphPad Software Inc., La Jolla, CA, USA).

\section{Results}

\section{SNPs and haplotypes of CYP21A2 in AAD patients and HC}

The common exon variants p.9_10insL/g.1705_1706 insCTG (rs397515394), p.K102R/g.2361A>G (rs6474), p.N493S/g.4377A $>$ G (rs6473), the intron 2 variant g.2333C $>$ A (rs6467) and the intron 3 variant g.2538 C > T (rs76565726) were frequently detected in both AAD and HC (Table 1). Conversely, p.S268T/g.3323 G>C (rs6472) appeared rarely (Table 1 ). Several other silent and intron variants were also detected in both $\mathrm{AAD}$ patients and $\mathrm{HC}$

Table 1 Differences in genotype frequencies (\%) of the most common variants in CYP21A2 detected in patients with autoimmune Addison's disease (AAD) and healthy controls (HC).

\begin{tabular}{l}
\hline CYP21A2 SNP \\
\hline rs397515394 \\
AAD \\
HC \\
rs6467 \\
AAD \\
HC \\
rs6474 \\
AAD \\
HC \\
rs76565726 \\
AAD \\
HC \\
rs6472 \\
AAD \\
HC \\
rs6473 \\
AAD \\
HC \\
\hline
\end{tabular}

\begin{tabular}{ccc}
\hline & Genotype & \\
\hline$+/+$ & $+/-$ & $-/-$ \\
$129(35)$ & $204(55.3)$ & $36(9.8)$ \\
$161(48.3)$ & $142(42.6)$ & $30(9.0)$ \\
AA & $\mathrm{AC}$ & $\mathrm{CC}$ \\
$72(19.6)$ & $198(54)$ & $97(26.4)$ \\
$107(32.5)$ & $153(46.5)$ & $69(21.0)$ \\
$\mathrm{GG}$ & $\mathrm{GA}$ & $\mathrm{AA}$ \\
$130(35.2)$ & $204(55.3)$ & $35(9.5)$ \\
$155(47.0)$ & $144(43.6)$ & $31(9.4)$ \\
$\mathrm{CC}$ & $\mathrm{CT}$ & $\mathrm{TT}$ \\
$118(32.0)$ & $211(57.2)$ & $40(10.8)$ \\
$157(47.6)$ & $134(40.6)$ & $39(11.8)$ \\
$\mathrm{GG}$ & $\mathrm{GC}$ & $\mathrm{CC}$ \\
$370(97.4)$ & $10(2.6)$ & $0(0)$ \\
$277(85.0)$ & $45(13.8)$ & $4(1.2)$ \\
$\mathrm{GG}$ & $\mathrm{GA}$ & $\mathrm{AA}$ \\
$131(34.6)$ & $214(56.5)$ & $34(9.0)$ \\
$156(48.3)$ & $139(43.0)$ & $28(8.7)$ \\
\hline
\end{tabular}

\begin{tabular}{ccc}
\hline P value & & OR \\
\cline { 1 - 1 } 0.001 & & 1.79 \\
0.0005 & & 1.92 \\
0.005 & & 1.69 \\
0.00003 & & 2.10 \\
$3.3 \times 10^{-9 *}$ & 0.15 \\
0.001 & \\
\hline
\end{tabular}

\begin{tabular}{|c|c|}
\hline $95 \% \mathrm{Cl}$ & $P$ value \\
\hline $\begin{array}{c}+I+\text { vs }+I- \\
1.31-2.46\end{array}$ & 0.0003 \\
\hline $\begin{array}{l}\text { AA vs } A C \\
1.33-2.77\end{array}$ & 0.0004 \\
\hline $\begin{array}{l}\text { GG vs GA } \\
1.23-2.32\end{array}$ & 0.001 \\
\hline $\begin{array}{l}\text { CC vs CT } \\
1.52-2.89\end{array}$ & $6.1 \times 10^{-6}$ \\
\hline $\begin{array}{c}\text { G vs C } \\
0.08-0.30\end{array}$ & $3.8 \times 10^{-10}$ \\
\hline $\begin{array}{l}\text { GG vs GA } \\
1.34-2.51\end{array}$ & 0.0002 \\
\hline
\end{tabular}

$P$ values were calculated by $\chi^{2}$ test for $2 \times 3$ tables and Fisher's exact test on $2 \times 2$ tables.

${ }^{*}$ Fisher's exact test. 
(listed in Supplementary Table 1, see section on supplementary data given at the end of this article), but were not further investigated in the large cohort.

For the rs397515394, rs6474 and rs6473 SNPs, the heterozygote genotype occurred significantly $(P \leq 0.001)$ more often in patients with AAD than in $\mathrm{HC}$, compared with the homozygote genotype of the major alleles (Table 1). Haplotype reconstruction of CYP21A revealed that $\div \mathrm{AA}$ and $+\mathrm{GG}$ (in the order rs397515394/ rs6474/rs6473, from now denoted as the $\div$ AA and + GG haplotypes) mainly occurred together (Supplementary Table 2 , see section on supplementary data given at the end of this article), with a strong $\operatorname{LD}\left(r^{2}>0.87, D^{\prime}>0.94\right.$, Fig. $1 \mathrm{a}$ and $\mathrm{b}$ ). The frequencies of these haplotypes were significantly different between AAD patients and $\mathrm{HC}$ $(P=0.006)$, where $35.7 \%$ AAD patients and $28.2 \% \mathrm{HC}$ had the haplotype $\div \mathrm{AA}$, and $61.6 \%$ AAD patients and $67.7 \% \mathrm{HC}$ had the haplotype $+\mathrm{GG}$. Other combinations of these SNPs were seen in $2.8 \%$ of AAD patients and $4.1 \%$ of HC.

Regarding the intron variants rs6467 and rs76565726, the heterozygote genotype and the minor alleles were also more common in AAD than in $\mathrm{HC}$ (Table 1). The frequency of rs6467C was $53.4 \%$ in the AAD group, compared with $44.2 \%$ in $\mathrm{HC}(\mathrm{OR}=1.44$, 95\% CI $(1.17-$ 1.79), $P=0.007)$. The allele frequencies of $\mathrm{rs} 76565726 \mathrm{~T}$ were $39.4 \%$ in $\mathrm{AAD}$ and $32.1 \%$ in $\mathrm{HC}(\mathrm{OR}=1.38,95 \% \mathrm{CI}$ (1.10-1.72), $P=0.005)$. The majority of the rs76565726T alleles were seen together with the +GG haplotype, but never with the $\div$ AA haplotype (Supplementary Table 2 ), and was almost in complete LD with all these three coding SNPs $\left(D^{\prime}>0.97\right.$, Fig. $\left.1 \mathrm{~b}\right)$.

The rs6472C seemed to be a protective variant to AAD, where the allele frequency of the $\mathrm{C}$ allele was $8.1 \%$ in $\mathrm{HC}$

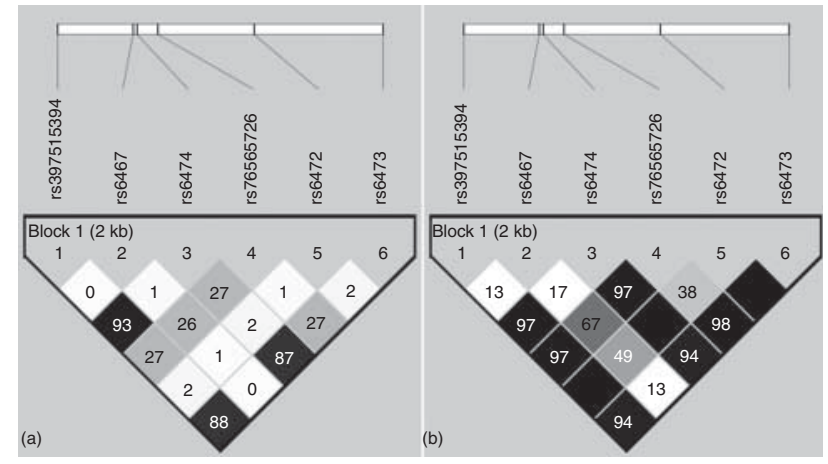

\section{Figure 1}

$r^{2}$ linkage plot (a) and $D^{\prime}$ linkage plot (b) of common variants of CYP21A2. compared with $1.3 \%$ in AAD patients $(\mathrm{OR}=0.15,95 \% \mathrm{CI}$ (0.08-0.30), $P=3.8 \times 10^{-10}$, Table 1$)$. The rs6472C allele was only seen together with the $+\mathrm{GG}$ variant of the rs397515394/rs6474/rs6473 haplotype (Supplementary Table 2), which was in complete LD $\left(D^{\prime}=1\right.$, Fig. $\left.1 \mathrm{~b}\right)$. The rs6472C allele in the AAD patients was mainly seen (nine of ten alleles) in the haplotype +CGTCG (in order rs397515394/rs6476/rs6474/rs76565726/rs6472/rs6473). In the control group, the haplotypes + AGTCG and + AGCCG were more frequent (22 and 23 of 53 rs6472C alleles, respectively, Supplementary Table 2).

\section{Are the CYP21A2 associations independent of HLA I and II loci?}

To this end, a global regression analysis was performed to determine whether AAD associations of CYP21A2 were independent $(P<0.05)$ of high-risk HLA loci. Table 2 gives that all the CYP21A2 SNPs associations, except rs6472 $(P=0.02)$, were lost when HLA-DRB1 was set as conditional marker, suggesting that the HLA-type determines the AAD-risk. The SNPs rs397515394, rs6472 and rs6473 showed independence from the HLA-DQB1 locus $(P=0.02$, $P=0.0002$ and $P=0.04$, respectively), while the rs6467, rs6474 and rs76565726 SNPs were in LD with $H L A-D Q B 1$ (Table 2). All the exon variants of $C Y P 21 A 2$ further showed independency to the $H L A-A, H L A-B$ and MICA, while the two intron variants were both in LD with $H L A-A$ and $M I C A$. The rs6467 was in LD with $H L A-B$, whereas rs76565726 was not $(P=0.02)$ (Table 2$)$.

We next wanted to investigate how CYP21A2 alleles are linked to the $H L A-D R B 1$ risk alleles. Supplementary Table 3 , see section on supplementary data given at the end of this article, gives the major CYP21A2 haplotypes (the SNPs rs397515394/rs6474/rs6472/rs6473 with haplotype $\div$ AGA and + GGG) in combination with the most common HLA-DRB1 haplotypes generated by PHASE. The $H L A-D R B 1{ }^{*} 0301$ mainly occurred together with the + GGG haplotype (i.e. $95.5 \%$ and $98.2 \%$ of AAD and HC respectively), while the $H L A-D R B 1{ }^{*} 04: 04$ haplotype was most commonly seen with the $\div$ AGA variant $(81.8 \%$ and $85.3 \%$ of AAD and HC cases respectively (Supplementary Table 3). The $H L A-D R B 1{ }^{*} 15$ and ${ }^{*} 01$ haplotypes also occurred most frequently together with the +GGG CYP21A2 haplotype, while the $H L A-D R B 1{ }^{*} 04: 01$ was most frequently seen together with $\div$ AGA (Supplementary Table 3). Furthermore, the individuals with heterozygous $H L A-D R B 1{ }^{*} 03: 01 /{ }^{*} 04: 04$ high-risk genotype were also heterozygote for $C Y P 21 A 2 \div \mathrm{AA} /+\mathrm{GG}$ in $81.7 \%$ AAD patients $(n=98)$ and $83.3 \% \mathrm{HC}(n=6)$ respectively. 
For rs6467, the $H L A-D R B 1{ }^{*} 03: 01$ haplotype was most frequently reconstructed together with the minor $\mathrm{C}$ allele, while the majority of $H L A-D R B 1{ }^{*} 04: 04,-{ }^{*} 15$ and - ${ }^{*} 01$ haplotypes were seen together with the A allele. For $H L A$ $D R B 1{ }^{*} 04: 01$, both rs6467 alleles were more equally distributed (Supplementary Table 3). For rs76565726 SNP, the minor $\mathrm{T}$ allele was mainly seen together with the $H L A-D R B 1{ }^{*} 03: 01$ haplotype (Supplementary Table 3).

The majority of the rs6472C alleles in AAD (six of ten) were reconstructed by PHASE together with the high-risk $H L A-D R B 1{ }^{*} 03: 01$, while the rest with $H L A-D R B 1{ }^{*} 07: 01$ (two of ten) and HLA-DRB1*13:01 (two of ten). For the HC group, the rs6472C allele was mainly seen together with the haplotypes $H L A-D R B 1$ *13:01 (19 of 53) - *01 (6 of 53) and $-{ }^{*} 07: 01$ (11 of 53). The protective effect of rs6472C was lost $(P>0.05)$ when considering the effect of the HLA-DRB1 haplotypes (Table 3).

\section{CYP21A2 variants related to biochemical and clinical parameters}

Although all of the patients in this study were diagnosed with $\mathrm{AAD}, 8 \%$ lacked $21 \mathrm{OH}-\mathrm{Ab}$ at the time of testing. Our analyses revealed that the frequencies of heterozygous variants of CYP21A2 were higher in the $21 \mathrm{OH}-\mathrm{Ab}$ positive group (Supplementary Table 4, see section on supplementary data given at the end of this article). The mean $21 \mathrm{OH}-\mathrm{Ab}$ levels at diagnosis were also higher in patients with the AAD-associated genotypes of CYP21A2, although not statistically significant (Supplementary Table 4).

Furthermore, the $H L A-D R B 1{ }^{*} 03: 01$ allele was found in 36.5 and $12.1 \%$ of $21 \mathrm{OH}-\mathrm{Ab}$ positives and negatives respectively. Likewise, for $H L A-D R B 1{ }^{*} 04: 04$, the allele frequency was 18.2 and $8.6 \%$ for $21 \mathrm{OH}-\mathrm{Ab}$ positives and negatives. $H L A-D R B 1{ }^{*} 04: 01$ and - * 15 were more common in the $21 \mathrm{OH}-\mathrm{Ab}$ negative group at 19 and $20.7 \%$, respectively, compared with 9.6 and $11.9 \%$ in the $21 \mathrm{OH}-\mathrm{Ab}$ positive group. Finally, the $H L A-D R B 1{ }^{*} 03: 01 /{ }^{*} 04: 04$ genotype was found only in $21 \mathrm{OH}-\mathrm{Ab}$ positives. The mean $21 \mathrm{OH}-\mathrm{Ab}$ levels at diagnosis were significantly higher in patients with the $H L A$ $D R B 1{ }^{*} 03: 01$ and - *04:04 haplotypes compared with other haplotypes, and similarly for the $H L A-D R B 1{ }^{*} 03: 01 /{ }^{*} 04: 04$ genotype $(P<0.0005)$. Patients with the $H L A-B^{*} 08$ had significantly higher $21 \mathrm{OH} \mathrm{Ab}$ indices at diagnoses compared with patients with other $H L A-B$ haplotypes $(P=0.028)$, while the $21 \mathrm{OH} \mathrm{Ab}$ indices were significantly higher in patients with the $H L A-A{ }^{*} 01$ compared with $H L A-A{ }^{*} 02(P=0.0031)$. The results are summarised in Supplementary Table 4.

The AAD-associated CYP21A2 variants were more frequent in patients with onset of the disease before 
Table 3 Haplotype reconstruction of protective and high risk alleles of HLA-DRB1 and rs6472.

\begin{tabular}{|c|c|c|c|c|c|c|}
\hline HLA-DRB1 & rs6472 & AAD & HC & ratio & $95 \% \mathrm{Cl}$ & $P$ value \\
\hline *1301 & C & 2 & 23 & 0.40 & $0.073-2.24$ & 0.44 \\
\hline *1301 & G & 6 & 19 & & & \\
\hline *0701 & C & 2 & 11 & 0.70 & $0.14-3.54$ & 1.0 \\
\hline *0701 & G & 14 & 54 & & & \\
\hline *01 & C & 0 & 11 & 0.11 & $0.006-2.01$ & 0.06 \\
\hline *01 & G & 23 & 61 & & & \\
\hline *0301 & G & 259 & 110 & 0.18 & $0.01-3.24$ & 0.18 \\
\hline *0301 & C & 6 & 0 & & & \\
\hline
\end{tabular}

$P$ values were calculated by Fisher's exact test.

40 years of age than in those with later onset. In addition, the protective variant rs6472C was not detected in patients with disease onset before 20 years (Supplementary Table 5 , see section on supplementary data given at the end of this article).

There was no association between autoimmune thyroid disease of the APS2 patients and the CYP21A2 variants. The rs76565726T allele was, however, more frequent in APS2 patients with type 1 diabetes than in AAD patients without type 1 diabetes $(\mathrm{OR}=1.517,95 \% \mathrm{CI}$ (1.027-2.240), $P=0.04)$, but there was no such association with the other CYP21A2 variants. There was no association between gender and CYP21A2 variants.

\section{Rare variants of CYP21A2 in AAD patients and HC}

A rare heterozygous coding variant, p.A159T/g.2637G $>$ A, was found in 3/370 patients with AAD and in 1/330 HC. All four were also heterozygous for the rare haplotype $H L A-B^{*} 4801$ which was absent in other patients and controls. Known disease causing mutations frequently reported in patients with $\mathrm{CAH}$ (34) were also found as heterozygous in both AAD patients and HC. The I2 splice variant (rs6467G) was detected in 2/370 AAD patients and 1/331 HC. The eight bp deletion in exon 3 (rs387906510) was found in one AAD patient and in one HC. The nonclassical CAH variant p.V281L (rs6471) was found in 3/380 AAD patients and 5/326 HC, while p.P453S (rs6445) was found in 3/379 AAD patients and 4/322 HC. No copy number variations were detected in AAD patients or $\mathrm{HC}$; they all had two copies of CYP21A2.

\section{Discussion}

It is not known why certain proteins, such as $210 H$, become autoantigens in organ-specific autoimmune diseases. However, common features are that autoantigens are intracellular enzymes with restricted tissue expression. One possibility is that only altered or modified selfproteins can induce autoreactive immune responses, and that genetic polymorphisms may represent such alterations. By direct sequencing of CYP21A2 in AAD patients, we did not find any disease-specific risk alleles, but heterozygous genotypes of common CYP21A2 variants were significantly more frequent in $\mathrm{AAD}$ patients than in HC. However, we found that all the CYP21A2 SNPs associations, except for rs6472, were dependent on the HLA-DRB1 locus, which is the strongest single genetic risk factor of $\operatorname{AAD}(2,4,35,36)$. Therefore, the higher heterozygous genotype frequency of the two main haplotypes of CYP21A2 alleles, $\div \mathrm{AA}$ and $+\mathrm{GG}$, merely reflects the high-risk genotype of $H L A-D R B 1{ }^{*} 03: 01 /{ }^{*} 04: 04$ (2). The protective rs6472C association could also be explained by the linkage with the HLA protective variants.

The non-coding AAD-associated CYP21A2 variants rs6467 and rs76565726 were also dependent on MICA and $H L A-A$ or $-B$. The rs76565726T allele was further associated with type 1 diabetes of the APS2 patients included in the study. Interestingly, the rs6467C and rs76565726T alleles have both shown to be in LD with components of the 8.1 ancestral haplotype (37).

Our data indicated that all of our patients with the $D R B 1{ }^{*} 03: 01 /{ }^{*} 04: 04$ genotype were positive for $21 \mathrm{OH} \mathrm{Ab}$ and had the highest $21 \mathrm{OH} \mathrm{Ab}$ indices compared with other genotypes. This is consistent of HLA$D R B 1{ }^{*} 03: 01 /{ }^{*} 04: 04$ genotype association with expression of $21 \mathrm{OH} \mathrm{Ab}$ (38). The corresponding CYP21A2 genotype did not add to the high $21 \mathrm{OH} \mathrm{Ab}$ association of $H L A$ $D R B 1{ }^{*} 03: 01 /{ }^{*} 04: 04$, which underlines the strength of $H L A-D R B 1$ risk factors. Similarly, we here found a trend for association between CYP21A2 genotypes and age of disease onset. This is in agreement with previous findings of a significant lower mean age of onset in patients who carries the $H L A-D R B 1{ }^{*} 03: 01 /{ }^{*} 04: 04$ genotype (2).

A hypothesis proposes that low protein expression due to genetic polymorphisms might increase the probability of autoreactive $\mathrm{T}$ cells to escape from the thymus during negative selection. This has been suggested for the variable number of tandem repeats polymorphism in the gene encoding insulin and its association with the production of $\mathrm{Ab}$ and autoreactive $\mathrm{T}$ cells to insulin in type 1 diabetes $(39,40)$. Although the HLA-DRB1 locus proves to be the highest predisposing factor of $\mathrm{AAD}$, the significance of CYP21A2 heterozygote genotypes is not clear because it is not known if the gene is inherited co-dominantly like the HLA genes. 
In conclusion, sequencing of the exons and introns of CYP21A2 did not reveal any disease-specific risk variants associated with AAD. Instead, CYP21A2 polymorphisms are in LD with the high-risk haplotypes of the HLA-DRB1 loci, and do not independently add to increased risk or protection, but merely reflects the effect of HLA-DRB1.

\section{Declaration of interest}

The authors declare that there is no conflict of interest that could be perceived as prejudicing the impartiality of the research reported.

\section{Supplementary data}

This is linked to the online version of the paper at http://dx.doi.org/10.1530/ EJE-12-0891.

\section{Funding}

The study was supported by grants from the Regional Health Authorities of Western Norway, Bergen Medical Research Foundation, The Norwegian Research council (project no. 213704) and the EU FP7 project Euradrenal (grant number 201167). I Brønstad is a PhD student supported by the University of Bergen.

\section{Acknowledgements}

The authors thank $\mathrm{H}$ Muneer, $\mathrm{E}$ Theodorsen and $\mathrm{E} \mathrm{T}$ Halvorsen for excellently organising DNA sampling and antibody analyses. They also thank all the patients and their medical doctors who have contribute to the National Norwegian Registry of patients with Addison's disease (ROAS).

\section{References}

1 Arlt W \& Allolio B. Adrenal insufficiency. Lancet 2003361 1881-1893. (doi:10.1016/S0140-6736(03)13492-7)

2 Erichsen MM, Lovas K, Skinningsrud B, Wolff AB, Undlien DE, Svartberg J, Fougner KJ, Berg TJ, Bollerslev J, Mella B et al. Clinical, immunological, and genetic features of autoimmune primary adrenal insufficiency: observations from a Norwegian registry. Journal of Clinical Endocrinology and Metabolism 200994 4882-4890. (doi:10.1210/ jc.2009-1368)

3 Husebye ES, Perheentupa J, Rautemaa R \& Kampe O. Clinical manifestations and management of patients with autoimmune polyendocrine syndrome type I. Journal of Internal Medicine 2009265 514-529. (doi:10.1111/j.1365-2796.2009.02090.x)

4 Skinningsrud B, Lie BA, Lavant E, Carlson JA, Erlich H, Akselsen HE, Gervin K, Wolff AB, Erichsen MM, Lovas K et al. Multiple loci in the HLA complex are associated with Addison's disease. Journal of Clinical Endocrinology and Metabolism 201196 E1703-E1708. (doi:10.1210/ jc.2011-0645)

5 Gambelunghe G, Falorni A, Ghaderi M, Laureti S, Tortoioli C, Santeusanio F, Brunetti P \& Sanjeevi CB. Microsatellite polymorphism of the MHC class I chain-related (MIC-A and MIC-B) genes marks the risk for autoimmune Addison's disease. Journal of Clinical Endocrinology and Metabolism 199984 3701-3707. (doi:10.1210/jcem.84.10.6069)

6 Park YS, Sanjeevi CB, Robles D, Yu L, Rewers M, Gottlieb PA, Fain P \& Eisenbarth GS. Additional association of intra-MHC genes, MICA and
D6S273, with Addison's disease. Tissue Antigens 200260 155-163. (doi:10.1034/j.1399-0039.2002.600206.x)

7 Triolo TM, Baschal EE, Armstrong TK, Toews CS, Fain PR, Rewers MJ, Yu L, Miao D, Eisenbarth GS, Gottlieb PA et al. Homozygosity of the polymorphism MICA5.1 identifies extreme risk of progression to overt adrenal insufficiency among 21-hydroxylase antibody-positive patients with type 1 diabetes. Journal of Clinical Endocrinology and Metabolism 200994 4517-4523. (doi:10.1210/jc.2009-1308)

8 Blomhoff A, Lie BA, Myhre AG, Kemp EH, Weetman AP, Akselsen HE, Huseby ES \& Undlien DE. Polymorphisms in the cytotoxic T lymphocyte antigen-4 gene region confer susceptibility to Addison's disease. Journal of Clinical Endocrinology and Metabolism 200489 3474-3476. (doi:10.1210/jc.2003-031854)

9 Brozzetti A, Marzotti S, Tortoioli C, Bini V, Giordano R, Dotta F, Betterle C, De Bellis A, Arnaldi G, Toscano V et al. Italian Addison N. Cytotoxic T lymphocyte antigen- 4 Ala17 polymorphism is a genetic marker of autoimmune adrenal insufficiency: Italian association study and meta-analysis of European studies. European Journal of Endocrinology 2010162 361-369. (doi:10.1530/EJE-09-0618)

10 Roycroft M, Fichna M, McDonald D, Owen K, Zurawek M, Gryczynska M, Januszkiewicz-Lewandowska D, Fichna P, Cordell H, Donaldson $\mathrm{P}$ et al. The tryptophan 620 allele of the lymphoid tyrosine phosphatase (PTPN22) gene predisposes to autoimmune Addison's disease. Clinical Endocrinology 200970 358-362. (doi:10.1111/ j.1365-2265.2008.03380.x)

11 Skinningsrud B, Husebye ES, Gervin K, Lovas K, Blomhoff A, Wolff AB Kemp EH, Egeland T \& Undlien DE. Mutation screening of PTPN22: association of the 1858T-allele with Addison's disease. European Journal of Human Genetics 200816 977-982. (doi:10.1038/ejhg.2008.33)

12 Skinningsrud B, Husebye ES, Pearce SH, McDonald DO, Brandal K, Wolff AB, Lovas K, Egeland $\mathrm{T} \&$ Undlien DE. Polymorphisms in CLEC16A and CIITA at 16p13 are associated with primary adrenal insufficiency. Journal of Clinical Endocrinology and Metabolism 200893 3310-3317. (doi:10.1210/jc.2008-0821)

13 Jennings CE, Owen CJ, Wilson V \& Pearce SH. A haplotype of the CYP27B1 promoter is associated with autoimmune Addison's disease but not with Graves' disease in a UK population. Journal of Molecular Endocrinology 200534 859-863. (doi:10.1677/jme.1.01760)

14 Lopez ER, Zwermann O, Segni M, Meyer G, Reincke M, Seissler J, Herwig J, Usadel KH \& Badenhoop K. A promoter polymorphism of the CYP27B1 gene is associated with Addison's disease, Hashimoto's thyroiditis, Graves' disease and type 1 diabetes mellitus in Germans. European Journal of Endocrinology 2004151 193-197. (doi:10.1530/ eje.0.1510193)

15 Mitchell AL, Cordell HJ, Soemedi R, Owen K, Skinningsrud B, Wolff AB Ericksen M, Undlien D, Husebye E \& Pearce SH. Programmed death ligand 1 (PD-L1) gene variants contribute to autoimmune Addison's disease and Graves' disease susceptibility. Journal of Clinical Endocrinology and Metabolism 200994 5139-5145. (doi:10.1210/ jc.2009-1404)

16 Winqvist O, Karlsson FA \& Kampe O. 21-hydroxylase, a major autoantigen in idiopathic Addison's disease. Lancet 1992339 1559-1562. (doi:10.1016/0140-6736(92)91829-W)

17 Betterle C, Scarpa R, Garelli S, Morlin L, Lazzarotto F, Presotto F, Coco G, Masiero S, Parolo A, Albergoni MP et al. Addison's disease: a survey on 633 patients in Padova. European Journal of Endocrinology 2013 169 773-784. (doi:10.1530/EJE-13-0528)

18 Falorni A, Laureti S, Nikoshkov A, Picchio ML, Hallengren B, Vandewalle CL, Gorus FK, Tortoioli C, Luthman H, Brunetti P et al. 21-hydroxylase autoantibodies in adult patients with endocrine autoimmune diseases are highly specific for Addison's disease. Belgian Diabetes Registry. Clinical and Experimental Immunology $1997 \mathbf{1 0 7}$ 341-346. (doi:10.1111/j.1365-2249.1997.262-ce1153.x)

19 Seissler J, Schott M, Steinbrenner H, Peterson P \& Scherbaum WA. Autoantibodies to adrenal cytochrome P450 antigens in isolated Addison's disease and autoimmune polyendocrine syndrome type II. 
Experimental and Clinical Endocrinology \& Diabetes 1999107 208-213. (doi:10.1055/s-0029-1212100)

20 Speiser PW, Azziz R, Baskin LS, Ghizzoni L, Hensle TW, Merke DP, Meyer-Bahlburg HF, Miller WL, Montori VM, Oberfield SE et al. Congenital adrenal hyperplasia due to steroid 21-hydroxylase deficiency: an Endocrine Society clinical practice guideline. Journal of Clinical Endocrinology and Metabolism 201095 4133-4160. (doi:10.1210/ jc.2009-2631)

21 White PC, New MI \& Dupont B. Structure of human steroid 21-hydroxylase genes. PNAS 198683 5111-5115. (doi:10.1073/pnas. 83.14.5111)

22 Wenzlau JM, Liu Y, Yu L, Moua O, Fowler KT, Rangasamy S, Walters J, Eisenbarth GS, Davidson HW \& Hutton JC. A common nonsynonymous single nucleotide polymorphism in the SLC30A8 gene determines ZnT8 autoantibody specificity in type 1 diabetes. Diabetes 200857 2693-2697. (doi:10.2337/db08-0522)

23 Dechairo BM, Zabaneh D, Collins J, Brand O, Dawson GJ, Green AP, Mackay I, Franklyn JA, Connell JM, Wass JA et al. Association of the TSHR gene with Graves' disease: the first disease specific locus. European Journal of Human Genetics 200513 1223-1230. (doi:10.1038/sj.ejhg.5201485)

24 Brand OJ, Barrett JC, Simmonds MJ, Newby PR, McCabe CJ, Bruce CK, Kysela B, Carr-Smith JD, Brix T, Hunt PJ et al. Association of the thyroid stimulating hormone receptor gene (TSHR) with Graves' disease. Human Molecular Genetics 200918 1704-1713. (doi:10.1093/hmg/ddp087)

25 Nikoshkov A, Falorni A, Lajic S, Laureti S, Wedell A, Lernmark K \& Luthman H. A conformation-dependent epitope in Addison's disease and other endocrinological autoimmune diseases maps to a carboxylterminal functional domain of human steroid 21-hydroxylase. Journal of Immunology 1999162 2422-2426.

26 Peterson P, Partanen J, Aavik E, Salmi H, Pelkonen R \& Krohn KJ. Steroid 21-hydroxylase gene polymorphism in Addison's disease patients. Tissue Antigens 199546 63-67. (doi:10.1111/j.1399-0039.1995.tb02478.x)

27 Wedell A \& Luthman H. Steroid 21-hydroxylase deficiency: two additional mutations in salt-wasting disease and rapid screening of disease-causing mutations. Human Molecular Genetics 19932 499-504. (doi:10.1093/hmg/2.5.499)

28 Wilson RC, Wei JQ, Cheng KC, Mercado AB \& New MI. Rapid deoxyribonucleic acid analysis by allele-specific polymerase chain reaction for detection of mutations in the steroid 21-hydroxylase gene. Journal of Clinical Endocrinology and Metabolism 199580 1635-1640. (doi:10.1210/jcem.80.5.7745011)

29 Lau IF, Soardi FC, Lemos-Marini SH, Guerra B Jr, Baptista MT \& De Mello MP. H28 + C insertion in the CYP21 gene: a novel frameshift mutation in a Brazilian patient with the classical form of 21-hydroxylase deficiency. Journal of Clinical Endocrinology and Metabolism 200186 5877-5880. (doi:10.1210/jcem.86.12.8113)
30 Parajes S, Quinterio C, Dominguez F \& Loidi L. A simple and robust quantitative PCR assay to determine CYP21A2 gene dose in the diagnosis of 21-hydroxylase deficiency. Clinical Chemistry 200753 1577-1584. (doi:10.1373/clinchem.2007.087361)

31 Barrett JC, Fry B, Maller J \& Daly MJ. Haploview: analysis and visualization of LD and haplotype maps. Bioinformatics 200521 263-265. (doi:10.1093/bioinformatics/bth457)

32 Dudbridge F. Likelihood-based association analysis for nuclear families and unrelated subjects with missing genotype data. Human Heredity 200866 87-98. (doi:10.1159/000119108)

33 Stephens M, Smith NJ \& Donnelly P. A new statistical method for haplotype reconstruction from population data. American Journal of Human Genetics 200168 978-989. (doi:10.1086/319501)

34 Wedell A. Congenital adrenal hyperplasia. Clinical Biochemistry 201144 505-506. (doi:10.1016/j.clinbiochem.2011.02.026)

35 Baker PR, Baschal EE, Fain PR, Triolo TM, Nanduri P, Siebert JC, Armstrong TK, Babu SR, Rewers MJ, Gottlieb PA et al. Haplotype analysis discriminates genetic risk for DR3-associated endocrine autoimmunity and helps define extreme risk for Addison's disease. Journal of Clinical Endocrinology and Metabolism 201095 E263-E270. (doi:10.1210/jc.2010-0508)

36 Yu L, Brewer GS, Gates S, Wu A, Wang T, Babu SR, Gottlieb PA, Freed BM, Noble J, Erlich HA et al. DRB1*04 and DQ alleles: expression of 21-hydroxylase autoantibodies and risk of progression to Addison's disease. Journal of Clinical Endocrinology and Metabolism 1999 84 328-335. (doi:10.1210/jcem.84.1.5414)

37 Blasko B, Banlaki Z, Gyapay G, Pozsonyi E, Sasvari-Szekely M, Rajczy K, Fust G \& Szilagyi A. Linkage analysis of the C4A/C4B copy number variation and polymorphisms of the adjacent steroid 21-hydroxylase gene in a healthy population. Molecular Immunology 200946 2623-2629. (doi:10.1016/j.molimm.2009.04.033)

38 Barker JM, Ide A, Hostetler C, Yu L, Miao D, Fain PR, Eisenbarth GS \& Gottlieb PA. Endocrine and immunogenetic testing in individuals with type 1 diabetes and 21-hydroxylase autoantibodies: Addison's disease in a high-risk population. Journal of Clinical Endocrinology and Metabolism 200590 128-134. (doi:10.1210/jc.2004-0874)

39 Durinovic-Bello I, Wu RP, Gersuk VH, Sanda S, Shilling HG \& Nepom GT. Insulin gene VNTR genotype associates with frequency and phenotype of the autoimmune response to proinsulin. Genes and Immunity 201011 188-193. (doi:10.1038/gene.2009.108)

40 Pugliese A, Zeller M, Fernandez A Jr, Zalcberg LJ, Bartlett RJ, Ricordi C, Pietropaolo M, Eisenbarth GS, Bennett ST \& Patel DD. The insulin gene is transcribed in the human thymus and transcription levels correlated with allelic variation at the INS VNTR-IDDM2 susceptibility locus for type 1 diabetes. Nature Genetics 199715 293-297. (doi:10.1038/ ng0397-293)

Received 28 May 2014

Revised version received 25 August 2014

Accepted 23 September 2014 